\title{
Suppression of Noxious Stimulus-Evoked Activity in the Ventral Posterolateral Nucleus of the Thalamus by a Cannabinoid Agonist: Correlation between Electrophysiological and Antinociceptive Effects
}

\author{
William J. Martin, Andrea G. Hohmann, and J. Michael Walker \\ Schrier Research Laboratory, Department of Psychology, Brown University, Providence, Rhode Island 02912
}

The CNS contains a putative cannabinergic neurotransmitter and an abundance of G-protein-coupled cannabinoid receptors. However, little is known about the function of this novel neurochemical system. Cannabinoid agonists produce antinociception in behavioral tests, suggesting the possibility that this system serves in part to modulate pain sensitivity. To explore this possibility, the effects of the cannabinoid agonist WIN 55,212-2 on nociceptive neurons in the ventroposterolateral (VPL) nucleus of the thalamus were examined in urethaneanesthetized rats. After identification of a nociresponsive neuron, a computer-controlled device delivered graded pressure stimuli to the contralateral hindpaw. WIN 55,212-2 (0.0625, 0.125 , and $0.25 \mathrm{mg} / \mathrm{kg}$, i.v.) suppressed noxious stimulusevoked activity of VPL neurons in a dose-dependent and reversible manner. Noxious stimulus-evoked firing was affected more than spontaneous firing. These effects were apparently mediated by cannabinoid receptors, because the cannabinoid receptor-inactive enantiomer of the drug (WIN 55,212-3, 0.25 $\mathrm{mg} / \mathrm{kg}$ ) failed to alter the activity of this population of cells. Administration of morphine $(0.5 \mathrm{mg} / \mathrm{kg}$, i.v.) produced effects that were very similar to those produced by the cannabinoid. WIN 55,212-2 (0.25 mg/kg, i.v.) failed to alter the responses of non-nociceptive low-threshold mechanosensitive neurons in the VPL. WIN 55,212-2 produced antinociceptive effects with a potency and time course similar to that observed in the electrophysiological experiments, despite the differences in the anesthetic states of the animals used in these experiments. The antinociceptive and electrophysiological effects on VPL neurons outlasted the motor effects of the drug. Furthermore, the changes in nociceptive responding could not be attributed to changes in skin temperature. Taken together, these findings suggest that cannabinoids decrease nociceptive neurotransmission at the level of the thalamus and that one function of endogenous cannabinoids may be to modulate pain sensitivity.

Key words: cannabinoid analgesia; tetrahydrocannabinol; anandamide; thalamus; nociception; rat
The identification of specific G-protein-coupled cannabinoid receptors (Howlett et al., 1990) and the discovery of anandamide (Devane et al., 1992), a putative ligand for these receptors, provide strong evidence for an endogenous cannabinergic neural system (for review, see Pertwee, 1993). These discoveries are the foundation for new research aimed at understanding the functions of endogenous cannabinoids. Although much is known about the pharmacology of cannabinoids, little is known about their actions on particular neural systems, and no definitive statements can be made about the functions of endogenous cannabinoids.

The high levels of cannabinoid receptors in the CNS suggest that endogenous cannabinoids are a major class of neuromodulators. Studies of the distribution of cannabinoid receptors revealed that they occur in concentrations that equal or exceed those of the most plentiful neurotransmitter receptors known

Received Feb. 26, 1996; revised July 24, 1996; accepted July 30, 1996.

W.J.M. was supported by graduate fellowships from the National Science Foundation and the National Institute on Drug Abuse (DA05617), and A.G.H. was supported by a predoctoral fellowship from the National Institute on Drug Abuse (DA05725). J.M.W. is grateful for the support of a Research Scientist Development Award from the National Institute of Mental Health (KO2-MH01083). This work was supported by a grant from the National Institute of Neurological Disorders and Stroke (NS33247). We express our gratitude to Professors Allan Basbaum, Eugene Delay, and Robert Patrick for their helpful comments on this manuscript; Therese Millette for editorial assistance; and Saundra L. Patrick for technical assistance.

Correspondence should be addressed to J. Michael Walker, Department of Psychology, P.O. Box 1853, 89 Waterman Street, Brown University, Providence, RI 02912.

Copyright (C) 1996 Society for Neuroscience $\quad 0270-6474 / 96 / 166601-11 \$ 05.00 / 0$
(Herkenham et al., 1991; Herkenham, 1995). With regard to the present investigations of the role of cannabinoids in pain modulation, it is notable that the concentration of cannabinoid receptors in spinal cord (Herkenham et al., 1991) is 10 to 50 times higher than the level of opiate receptors (Faull and Villiger, 1987; Besse et al., 1991). The high concentration of cannabinoid receptors in specific brain areas accounts for the powerful effects of cannabinoids on behavior and suggests that endogenous cannabinoids are a major neurochemical system in the brain.

Although there are no direct data on the functions of endogenous cannabinoids, administration of their synthetic counterparts suggests that endogenous cannabinoids modulate pain sensitivity. Exogenous cannabinoids reduce responsiveness to noxious thermal stimuli (Buxbaum, 1972; Sofia, 1973; Bloom et al., 1977; Jacob et al., 1981; Yaksh, 1981; Lichtman and Martin, 1991a,b), mechanical stimuli (Sofia et al., 1973), and chemical stimuli (Moss and Johnson, 1980) in rats and mice, with a potency and efficacy similar to that of morphine (Buxbaum, 1972; Bloom, 1977; Jacob et al., 1981). However, these compounds also suppress motor function (Loewe, 1946; Gough and Olley, 1977; Ueki, 1980) and decrease neurotransmission in the output pathways of the basal ganglia (Miller and Walker, 1995), raising questions about the interpretation of results from behavioral tests of pain sensitivity (Cartmell et al., 1991). Several recent studies suggest that cannabinoids suppress nociceptive processing at the level of the spinal cord (Lichtman et al., 1991a,b; Hohmann et al., 1995; Tsou et al., 
1996); however, the extent to which these effects are conserved throughout ascending sensory pathways is not known.

The spinothalamic tract plays an integral role in the transmission of nociceptive information from the spinal to supraspinal level (Mitchell and Hellon, 1977; Guilbaud et al., 1980; Peschanski et al., 1980a,b, 1983) (for review, see Willis, 1984). Originating primarily in the dorsal horn of the spinal cord, spinothalamic tract neurons terminate in several thalamic nuclei including the ventroposterolateral (VPL) nucleus (Lund and Webster, 1967; McAllister and Wells, 1981; Peschanski et al., 1983; Peschanski and Besson, 1984). The VPL nucleus receives inputs from spinal wide dynamic range neurons, which encode the strength of noxious and non-noxious stimuli (Mendell, 1966; Giesler et al., 1976) (see also Price, 1988). This specificity is maintained at the level of the VPL, at which somatotopically arranged neurons with relatively small receptive fields represent the location and intensity of noxious somatic stimuli (Peschanski et al., 1980a,b, 1983; Guilbaud et al., 1980, 1987). Furthermore, morphine suppresses the responses of VPL neurons to noxious stimuli (Hill and Pepper, 1978; Benoist et al., 1983), an important demonstration in view of the strategic location of the VPL within pain-processing circuitry.

The cannabinoid agonist WIN 55,212-2 was used throughout the experiments reported herein. The potency and selectivity of this compound and its ability to produce cannabinoid receptormediated behavioral and electrophysiological effects have been documented using both in vitro and in vivo approaches (Compton et al., 1992; D’Ambra et al., 1992; Jansen et al., 1992; Pertwee et al., 1993; Felder et al., 1995). Here, we describe experiments that demonstrate the following. (1) A cannabinoid agonist inhibits the activity of nociceptive neurons but not mechanosensitive neurons in the VPL of anesthetized rats in a manner similar to morphine. (2) There is a strong relationship between the electrophysiological and antinociceptive effects of the cannabinoid. (3) The cannabinoid's electrophysiological and antinociceptive actions can be dissociated from its effects on thermoregulation and motor function. Together these findings demonstrate that cannabinoids selectively inhibit nociceptive neurotransmission in rat spinothalamic tract neurons and suggest a possible function of a cannabinergic receptor system in the modulation of pain sensitivity.

\section{MATERIALS AND METHODS}

Drug preparation and administration. WIN 55,212-2 (Research Biochemicals International, Natick, MA) and WIN 55,212-3 (a gift from Dean A. Haycock, Sterling Research Group, Rensselaer, NY) were dissolved in a 1:1:18 mixture of ethanol: emulphor (Alkamuls EL-620, Rhone-Poulenc, Cranbury, NJ): saline. Morphine sulfate (Mallincrodt, Paris, KY) was dissolved in saline at a concentration of $0.5 \mathrm{mg} / \mathrm{ml}$. WIN 55,212-2 was prepared in concentrations of $0.0625,0.125$, and $0.25 \mathrm{mg} / \mathrm{ml}$. Drugs were administered in a volume of $1 \mathrm{ml} / \mathrm{kg}$ through the lateral tail vein.

\section{Electrophysiological methods}

Surgical preparation. For all electrophysiological experiments, male Sprague Dawley rats weighing 250-400 gm were anesthetized with urethane $(1.5 \mathrm{~g} / \mathrm{kg}$, i.p., supplemented as required) and placed in a stereotaxic frame. Body temperature was monitored and maintained at $37^{\circ} \mathrm{C}$ using an automated heating pad. The cortex above the VPL was exposed, the dura mater was excised, and the brain was kept moist with $0.9 \% \mathrm{NaCl}$.

Electrode preparation and recording. Single-barrel glass micropipettes were pulled in a Narashige PE2 puller; tips were broken back to $\sim 1 \mu \mathrm{m}$ diameter. The electrode was filled with a saturated solution of fast green dye in $2 \mathrm{M} \mathrm{NaCl}$. Electrode penetrations were made in the region of the VPL ( $-3.2 \mathrm{~mm}$ posterior, $-3.6 \mathrm{~mm}$ lateral, and -4.9 to $5.4 \mathrm{~mm}$ ventral from bregma) based on the atlas of Paxinos and Watson (1986). On isolation of a spontaneously active single neuron, its response to light brushing with a camel hair brush of the contralateral and ipsilateral hindpaws was examined. If the neuron was responsive to the stimulus, then its response to light pinching with forceps and joint movement was determined. Neurons that responded to brushing and pressure, but not to joint movement, were then tested for their responses to a graded pressure stimulus applied to the receptive field. Data were collected for $1 \mathrm{sec}$ before stimulus onset, during the $5 \mathrm{sec}$ of the stimulus application, and for an additional $5 \mathrm{sec}$ after termination of the stimulus. In all cases, drugs were tested on only one cell at one dose per animal.

Histology. At the end of each experiment, fast green dye was ejected by passing $30 \mu \mathrm{A}$ through the electrode (tip negative) for 20 min to mark the location of the recording site. Animals were perfused transcardially with $0.9 \% \mathrm{NaCl}$, followed by $10 \%$ formalin. Brains were removed and stored overnight in a $30 \%$ sucrose-formalin solution. Frozen sections $(40 \mathrm{~mm})$ were mounted, stained with neutral red, and examined microscopically to localize the recording site. Data from a particular subject were included in the study only if histological examination revealed that the recording was obtained from a neuron within the boundaries of the VPL.

Administration of noxious pressure. A computer-controlled miniature air cylinder (described by Hohmann et al., 1995) was used to administer the pressure stimulus. The stimulus was $5 \mathrm{sec}$ in duration, rising continuously from zero pressure to a peak of $4.6 \mathrm{~kg} / \mathrm{cm}^{2}$ over a $3 \mathrm{sec}$ period and held for $2 \mathrm{sec}$.

Experimental procedure. Baseline responses to the noxious pressure stimulus were determined by applying the stimulus 10 times at $1 \mathrm{~min}$ intervals. The drug or vehicle was then injected intravenously, and the stimulus was applied at $1 \mathrm{~min}$ intervals for $10 \mathrm{~min}$. To follow the recovery from the effects of the drug, a 10 min rest period was allowed; then the stimulus was delivered every 2 min until the responses returned to within $20 \%$ of baseline.

Data acquisition. The output of the preamplifier was connected to an electronic circuit that produced a logic pulse for each action potential. The output was passed to a computer, which stored the time of occurrence of each action potential $(0.1 \mathrm{msec}$ accuracy $)$ and produced a graphical display of the data as they were acquired.

Classification of nociresponsive neurons. Stimulus-response functions were calculated from pretreatment baseline data by plotting the firing rate against the mean applied pressure during the increasing portion of the stimulus $(0-3 \mathrm{sec})$. Preliminary analyses indicated that the stimulusresponse functions were logarithmic rather than linear. Therefore, the values for firing rate and pressure were subjected to logarithmic transformation followed by linear regression analysis. Only neurons that exhibited stimulus-response functions with a slope of at least 0.2 and an $r$ value of at least 0.5 were classified as wide dynamic range neurons and included in the study.

Examination of responses of non-nociceptive mechanosensitive neurons to non-noxious stimuli after WIN 55,212-2. Non-nociceptive mechanosensitive neurons $(n=5)$ were recorded in the VPL using methods based on those described by others (Angel and Clark 1975; Dong et al., 1978; Peschanski et al., 1981; Miletic and Coffield, 1989; Montagne-Clavel and Oliveras, 1995). These neurons usually exhibited little or no spontaneous activity; therefore, a search stimulus (light tapping with a wooden probe) was used to identify candidate neurons. Once isolated, the receptive field of the neuron was mapped on the plantar surface of the contralateral hindpaw using an insect pin, and the region that yielded maximal responses was marked in ink. Activity was evoked in these cells using a light-touch stimulus, which consisted of gently tapping the receptive field with a rounded wooden probe ( $3 \mathrm{~mm}$ diameter). Tapping the skin within the receptive field of the neuron produced reliable and reproducible activation of mechanosensitive neurons. These neurons were characterized as non-nociceptive based on the lack of a greater response to the noxious pressure stimulus $\left(4.6 \mathrm{~kg} / \mathrm{cm}^{2}\right)$ than to the light-touch stimulus. The light-touch stimulus was applied at the same intervals and for the same duration as the pressure stimulus used to evoke activity in wide dynamic range neurons in the VPL. After baseline responses were established, the effect of the high dose of WIN $55,212-2(0.25 \mathrm{mg} / \mathrm{kg})$ on activity evoked in these neurons by the non-noxious stimulus was examined.

Data analysis. As noted above, all electrophysiological data were stored as the time of occurrence of each action potential. These data were transformed into firing rates (mean number of action potentials/duration of the interval) for successive intervals before and after administration of the stimulus using computer programs written by the investigators on a Hewlett-Packard 9000/720 workstation. These data were used to construct the peristimulus time histograms (PSTHs) shown in the figures. Similar techniques were used to determine the mean stimulus pressure at different times, which were combined with the calculated firing rates to 
construct stimulus-response functions. These data were transferred to an IBM mainframe for statistical analysis using BMDP Statistical Software (Los Angeles, CA). ANOVA and appropriate post hoc tests were used to analyze treatment effects. The Greenhouse-Geiser (1959) correction was applied to interaction terms containing a repeated factor.

The effects of various drug treatments on stimulus-response functions of nociceptive neurons were determined by calculating the mean response for each drug condition and performing a linear regression on the $\log _{10}$-transformed mean firing rates against the $\log _{10}$-transformed mean pressures using the method of least squares. Estimation of $95 \%$ confidence intervals for slope was determined using the method described by Goldstein (1964). The significance of the correlation coefficients was determined by ANOVA. Differences among the slopes of the mean stimulus-response functions were assessed using the method described by Edwards (1984), and the $p$ value was adjusted to account for multiple comparisons by the Bonferroni method (Myers, 1972).

The duration of the electrophysiological effects was calculated as the interval during which responses deviated from predrug levels by $>20 \%$.

\section{Behavioral methods}

Antinociceptive effects of WIN 55,212-2: mechanical stimulation. A separate experiment was performed to examine the effect of WIN 55,212-2 on the behavioral response to the noxious pressure stimulus. In this experiment, the threshold of the withdrawal reflex to the computer-controlled mechanical pressure stimulus was determined. Because of the nature of the apparatus, it was necessary to lightly anesthetize rats $(n=12)$ for this experiment. This was accomplished by intraperitoneal injection of urethane $(1 \mathrm{gm} / \mathrm{kg})$, which produced a reduction in motor tone without suppressing nociceptive withdrawal or corneal reflexes. A hindpaw was placed in the pressure device, and the noxious stimulus used in the electrophysiological experiments was applied; electrophysiological responses were not recorded during this procedure. Throughout the period of stimulation, the pressure within the air cylinder was digitized (10 samples/sec) by a computer for later determination of the pressure at which a nociceptive withdrawal reflex occurred. When a withdrawal reflex occurred (judged by a sudden and vigorous withdrawal flexion of the hindlimb), the stimulus was immediately removed, the pressure at which the response occurred was recorded, and a 3 min interval was allowed to pass before the next test. After a stable baseline was established, either WIN $55,212-2(0.25 \mathrm{mg} / \mathrm{kg}$, i.v. $)$ or vehicle was administered, and the rat was tested at $3 \mathrm{~min}$ intervals for the next $60 \mathrm{~min}$.

Antinociceptive effects of WIN 55,212-2: thermal stimulation. A second experiment was performed to further examine the relationship between the effects of the drug on behavioral and electrophysiological responses to noxious stimuli. This experiment used awake animals $(n=20)$ and an established measure of pain sensitivity, that is, the tail flick test of D'Amour and Smith (1941). Initially, the radiant heat source was adjusted to produce tail-flick latencies in the range of $2.5-4.5 \mathrm{sec}$. Then the latency to withdraw the tail from the noxious thermal stimulus was recorded every $3 \mathrm{~min}$ for $15 \mathrm{~min}$. WIN 55,212-2 (0, 0.0625, 0.125, 0.25 $\mathrm{mg} / \mathrm{kg}$ ) was administered intravenously via the lateral tail vein, and testing resumed for the following $45 \mathrm{~min}$ or until latencies returned to within $20 \%$ of baseline. Time-effect curves were constructed as the percent maximal possible effect (\%MPE) derived from the following equation:

$$
\% \mathrm{MPE}=\frac{\text { test latency }- \text { control latency }}{\text { cut-off latency }- \text { control latency }} \times 100
$$

where the control latency equaled the mean of three predrug baseline tests, and the cut-off latency was $10 \mathrm{sec}$.

Measurement of tail and paw temperature. It has been reported that changes in skin temperature can lead to artifactual changes in apparent pain sensitivity (Tjolsen et al., 1989). Therefore, the effects of the vehicle and WIN 55,212-2 on skin temperature were examined in two experiments, one under conditions similar to those used in the electrophysiological experiments and another under conditions similar to those used in the behavioral experiments. In the first experiment, sham-operated rats $(n=3)$ were anesthetized with urethane, positioned on a feedbackcontrolled heating pad, and secured in a stereotaxic frame, as described for the electrophysiology experiments. A craniotomy was performed over the VPL, and the dura mater was excised. After $\sim 1.5 \mathrm{hr}$ of acclimatization to the heating pad, skin temperature was measured by means of a copper-constantan type $\mathrm{T}$ thermocouple probe (diameter $=1.2 \mathrm{~mm}$, Teflon insulated) (Omega Engineering, Stamford, CT), which was fastened to the hindpaw with adhesive tape. Baseline readings of skin temperature were recorded at $3 \mathrm{~min}$ intervals for $15 \mathrm{~min}$ before intravenous administration of WIN 55,212-2 $(0.25 \mathrm{mg} / \mathrm{kg})$ and continued at 3 min intervals for the subsequent $60 \mathrm{~min}$.

To examine further the possibility that the drug altered nociceptive responses by changing skin temperature, tail skin temperature was recorded in awake animals at $3 \mathrm{~min}$ intervals for $15 \mathrm{~min}$ before and $120 \mathrm{~min}$ after administration of either WIN $55,212-2(0.25 \mathrm{mg} / \mathrm{kg}$, i.v. $)$ or the vehicle $(n=13)$. The procedure for measuring temperature was the same as described above, except that the thermoprobe was attached to the ventral surface of the tail where the thermal stimulus is normally applied for tail-flick testing.

Effects of WIN 55,212-2 on motor function. To examine the relationship between the antinociceptive and motor effects of the drug, motor function was assessed using two different measures, and the time course of the effects of WIN 55,212-2 was recorded. The first study used the rotorod procedure, a sensitive measure of motor coordination (Dunham and Miya, 1957; Kinnard and Carr, 1957). A second study, which was performed in a separate group of rats, examined the cataleptic effects of WIN 55,212-2.

A $6 \mathrm{~cm}$ rotorod treadmill (UGO Basile model 7700, Stoelting, Chicago, IL) was set to rotate at a constant speed of $10 \mathrm{rpm}$. Rats $(n=16)$ were trained to run continuously for 2 min during two training sessions separated by 1-2 hr. After this criterion was achieved, animals received injections of either WIN 55,212-2 (0.25 mg/kg, i.v.) or vehicle. Animals were tested for their ability to remain on the rotorod at 5 postinjection times $(5,10,20,30$, and $60 \mathrm{~min})$. If a fall occurred during the test session, the animal was immediately returned to the rotorod, and the mean duration on the treadmill was calculated for the two attempts.

Catalepsy was measured using a bar test similar to that described by Pertwee and Wickens (1991). Each rat $(n=6)$ was placed with both forelegs over a horizontal stainless steel bar (diameter $=0.5 \mathrm{~cm}) 9 \mathrm{~cm}$ above a Plexiglas base. The latency to descend from the bar was used as the index of catalepsy. The test was performed before injection of WIN $55,212-2(0.25 \mathrm{mg} / \mathrm{kg}, \mathrm{i.v}$.$) and at 3 \mathrm{~min}$ intervals for $30 \mathrm{~min}$ thereafter. A maximum descent latency of $60 \mathrm{sec}$ was allowed.

Data analysis. ANOVA was used to assess changes in nociceptive responding, skin temperature, and motor function. As with the electrophysiological studies, the duration of the drug effects for the measures described above (withdrawal from noxious pressure, tail flick, catalepsy, rotorod) was determined by calculating the time during which responding deviated from the mean predrug response by $>20 \%$. The data from the experiments on catalepsy were analyzed by the nonparametric sign test, because of floor and ceiling effects. $p<0.05$ was considered statistically significant in all experiments.

The experiments reported herein were approved by the Brown University Institutional Animal Care and Use Committee.

\section{RESULTS}

A total of 32 nociceptive and 5 non-nociceptive neurons were recorded in the VPL. As shown in Figure 1, neurons were found in the region of VPL observed previously to contain neurons with receptive fields on the contralateral hindpaw (Angel and Clark, 1975).

\section{Characterization of nociresponsive VPL neurons}

The nociresponsive neurons included in this study fired spontaneously at a mean rate of $4.6 \pm 0.6 \mathrm{~Hz}(\mathrm{SEM})$ and responded to the increasing intensity of the pressure stimulus with increases in firing rate (Fig. $2 A$ ). The peak mean firing rate of all nociceptive neurons recorded in the VPL (measured before drug treatment) was $14.6 \pm 0.6 \mathrm{~Hz}$, which occurred during maximum stimulus pressure. A repeated-measures ANOVA was performed on all 32 nociceptive cells for the 10 predrug baseline trials. Data were extracted from 20 successive time intervals, during which stimulus strength was continuously increasing. This analysis revealed that firing rate increased as a function of pressure $\left(F_{(19,494)}=33.74\right.$, $p<0.00005)$. There were no significant differences in the evoked response across baseline trials or among the drug groups for either preinjection spontaneous firing rate or stimulus-evoked firing rate. 
Figure 1. Reconstruction of the anatomical locations of neurons recorded in this study. Sections through the right diencephalon were redrawn according to the atlas of Paxinos and Watson (1986). Heavy black lines outline the VPL nucleus of the thalamus. Filled circles show the location of nociceptive neurons, whereas open circles show the location of non-nociceptive neurons included in the study.

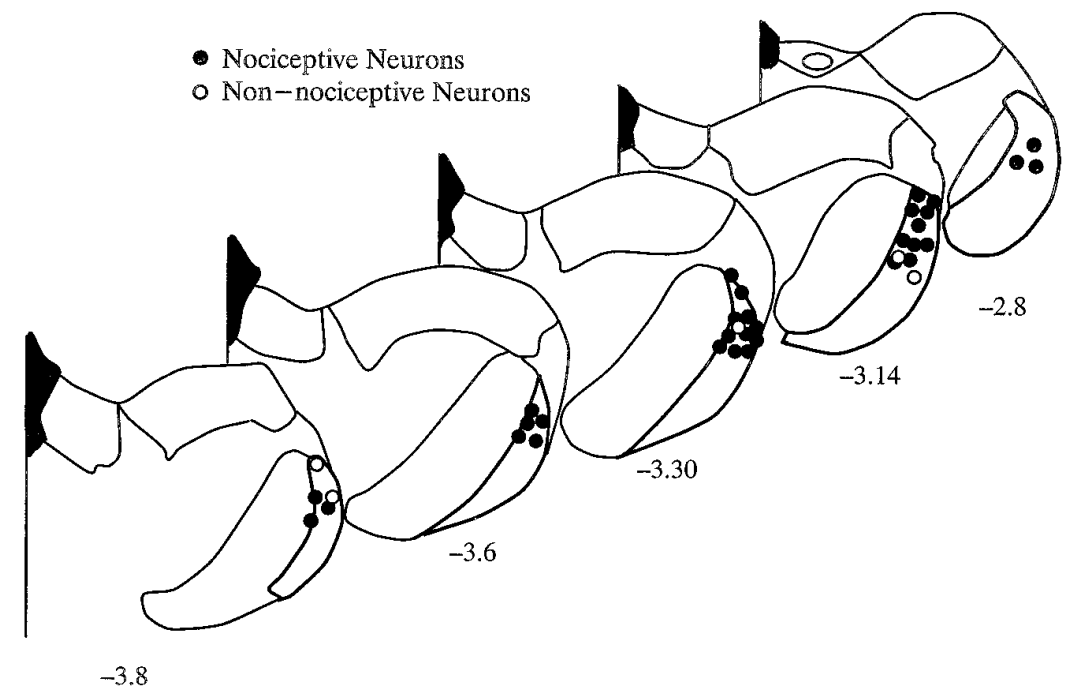

The mean slope of the preinjection (log-log) stimulus-response function of the 32 nociresponsive neurons examined was 0.84 ( $n=$ $32, r=0.990$ ) (Fig. 2B). This population of neurons may be classified as wide dynamic range type, because each cell showed a graded response over a wide range of stimulus intensities including noxious levels.

\section{Lack of effect of vehicle and the cannabinoid receptor- inactive enantiomer WIN 55,212-3}

Neither the vehicle nor WIN 55,212-3, the cannabinoid receptorinactive enantiomer, altered the responses of the nociceptive neurons in the VPL to the noxious pressure stimulus (Fig. $3 A$ ). Repeated-measures ANOVA was performed to compare the mean response with 10 presentations of the stimulus (at various pressure levels including zero pressure during pre- and poststimulus periods) before and after injection of enantiomer or vehicle. Separate analyses failed to reveal any effects of either the vehicle or WIN 55,212-3.

\section{Effects of WIN 55,212-2 on nociceptive neurons}

ANOVA revealed that WIN 55,212-2 (0.0625, 0.125, $0.25 \mathrm{mg} / \mathrm{kg}$, i.v.) decreased both spontaneous and noxious stimulus-evoked activity $\left(F_{(3,19)}=12.88, p<0.0001\right)$ (Fig. $\left.3 B, C\right)$. As shown in Figure 4 , there were dose-dependent differences in the times that the drug significantly suppressed nociceptive stimulus-evoked activity.

Although WIN 55,212-2 decreased both spontaneous and evoked firing rates, the drug produced a greater effect on evoked firing (Fig. 5). ANOVA compared the rate of spontaneous firing after the vehicle and various doses of WIN 55,212 during the (1 sec) prestimulation period to the firing rate during the last (most noxious) second of stimulation. The significant interaction between drug treatment and stimulation condition in this analysis revealed a larger effect of the drug on noxious stimulus-evoked firing than on spontaneous firing $\left(F_{(3,19)}=11.41, p=0.0002\right)$ (Fig. 5).

WIN 55,212-2 produced dose-dependent changes in the slopes of the stimulus-response functions (Fig. 6). The slope of the stimulus-response function after injection of the lowest dose of the drug was not significantly different from that observed after the vehicle. However, the slopes of the mean stimulus-response functions obtained after the doses of 0.125 and $0.25 \mathrm{mg} / \mathrm{kg}$ WIN 55,212-2 were more shallow than those obtained after the vehicle ( $p<0.05$ for both comparisons). The slopes of the mean stimu- lus-response functions after the two higher doses did not differ from each other. At the highest dose of the drug $(0.25 \mathrm{mg} / \mathrm{kg})$, the slope stimulus-response function was only $0.1(p>0.05)$, and its 95\% confidence limits included zero (i.e., a horizontal line), indicating that the neurons were unable to encode stimulus strength with increasing firing rates.

Morphine $(0.5 \mathrm{mg} / \mathrm{kg}$, i.v. $)$ also decreased the responsiveness of neurons in VPL $\left(F_{(1,4)}=13.9, p=0.02\right)$ (Fig. 7). Like the cannabinoid, morphine produced a marked downward shift of the stimulus-response function. As shown in Figure 7, the effect of morphine $(0.5 \mathrm{mg} / \mathrm{kg})$ was very similar to that produced by 0.0625 $\mathrm{mg} / \mathrm{kg}$ WIN 55,212. The slopes of the stimulus-response functions for these two treatments did not differ.

\section{Lack of effect of WIN 55,212-2 on non-nociceptive mechanosensitive neurons in VPL}

A matched-pairs $t$ test was used to compare firing evoked in non-nociceptive cells by the non-noxious stimulus with that evoked by the noxious pressure stimulus. This analysis failed to reveal a significant difference between firing rate during nonnoxious and noxious stimulation $\left[T_{4}=1.34, p>0.05\right.$, nonsignificant (ns); mean firing rate \pm SEM: $4.1 \pm 1.1$ vs $2.6 \pm 0.8 \mathrm{~Hz}$ for non-noxious and noxious levels of evoked activity, respectively]. The cannabinoid failed to suppress activity evoked by the nonnoxious tap stimulus $\left(F_{(1,4)}=1.24, p=0.33\right.$, ns; mean firing rate \pm SEM: $4.1 \pm 1.1$ vs $4.6 \pm 1.0 \mathrm{~Hz}$ for pre- and postinjection mean levels of evoked activity, respectively) (see Fig. 10). In fact, the drug appeared to increase the signal-to-noise ratio of some cells (e.g., Fig. 8); i.e., background firing slowed, and the cells exhibited a sharper response to the tap stimulus.

\section{Lack of effect of WIN 55,212-2 on paw temperature in anesthetized rats}

Repeated-measures ANOVA conducted on the skin temperature readings obtained over time from the plantar surfaces of the hindpaws of animals treated with WIN 55,212-2 (0.25 mg/kg, i.v.) $(n=3)$ failed to reveal any drug effects on skin temperature. The overall change in mean pre- and postinjection skin temperature was only $0.6^{\circ} \mathrm{C}$ (mean $\pm \mathrm{SEM}: 31.7 \pm 0.3$ vs $31.1 \pm 0.3^{\circ} \mathrm{C}$ for preand postinjection, respectively). 

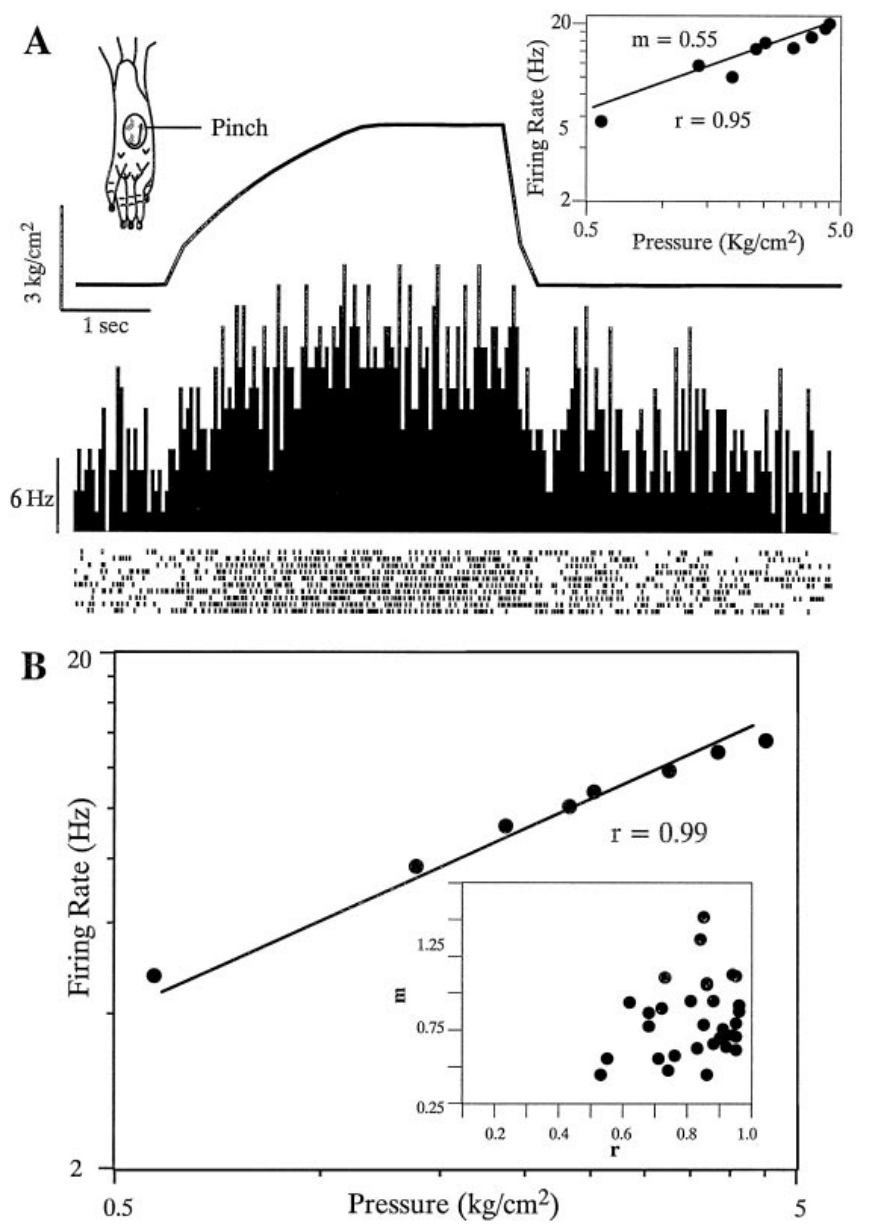

Figure 2. A, Example of a PSTH for a single VPL neuron before drug treatment. Top left, Site of application of the noxious pressure stimulus. Top center, Level of the applied pressure in register with the PSTH below. Top right, The stimulus-response function (pressure vs firing rate) of this cell. Bottom, Raster plot showing firing pattern of neuron. A single dot represents the occurrence of a single action potential; rows represent successive applications of the stimulus. The increased density of dots during the stimulus illustrates the increased firing rate of the neuron. $B$, Mean predrug stimulus-response functions for all nociceptive neurons included in the study $(n=32)$. The data used in the regression were derived by averaging the preinjection stimulus-evoked firing rate during the graded portion of the stimulus to obtain estimates of the mean firing rate at eight (mean) levels of pressure. The logarithms of the mean firing rates and pressures were subjected to linear regression. This yielded a slope of 0.84 for the mean stimulus-response function and a correlation coefficient of 0.99. Inset, Scatter plot of slope of predrug stimulus-response function versus correlation coefficient for all nociceptive neurons used in the study. All neurons exhibited a correlation coefficient of at least 0.5 ; the slopes of the $\log _{10}$ transforms of stimulus-response functions in untreated animals ranged from 0.2 to 1.25 .

\section{Tail skin temperature changes in awake rats after injections of WIN 55,212-2 and vehicle}

Repeated-measures ANOVA on the pre- and postinjection measures of tail skin temperature in awake rats revealed neither a significant overall difference between the effects of vehicle and WIN 55,212-2 nor a significant interaction effect (drug treatment across measurement times). However, there was a significant effect of testing time $(n=13)\left(F_{(38,418)}=3.13, p=0.03\right)$ attributable to a short-lived but consistent increase in temperature 3 min after injection (mean increase $=2.8^{\circ} \mathrm{C}$ ). The lack of any significant differences or interactions involving drug groups, to- gether with the rapid onset ( $3 \mathrm{~min}$ ) and brief duration of the effect (return to within $0.87^{\circ} \mathrm{C}$ of mean baseline temperature within 3 min), suggests that this was a nonspecific effect of the intravenous injection in the tail vein.

\section{Relationship between antinociceptive and electrophysiological effects}

To determine the magnitude and duration of the effects of WIN $55,212-2(0.25 \mathrm{mg} / \mathrm{kg}$, i.v. $)$ on paw withdrawal, a repeatedmeasures ANOVA, blocked by time (12 min/block), was performed. Consistent with previous findings (Hohmann et al., 1995), baseline withdrawal responses occurred at a mean pressure of $3.0 \pm 0.3 \mathrm{~kg} / \mathrm{cm}^{2}$ in sedated rats. WIN 55,212-2 increased the pressure required to elicit a nociceptive paw-withdrawal reflex to $4.0 \pm 0.3 \mathrm{~kg} / \mathrm{cm}^{2}\left(F_{(5,50)}=3.00, p<0.05\right)$. Ten minutes after drug administration, three of six animals failed to respond to the pressure stimulus before it was terminated at its maximal pressure of $4.6 \mathrm{~kg} / \mathrm{cm}^{2}$. Antinociception was observed in this test for $>30$ min (Table 1). Thus, the duration of the antinociceptive effect was very similar to the duration of the change in responsiveness of nociceptive neurons in the VPL (Fig. 9A). WIN 55,212-2 (0.0625 to $0.5 \mathrm{mg} / \mathrm{kg}$, i.v.) also produced dose-dependent elevations in tail-flick latencies (Fig. 9B). Furthermore, a comparison of the effect of WIN 55,212-2 on firing rate and tail-flick latencies revealed a strong correlation $(r=0.99)$ between the inhibition of noxious stimulus-evoked activity at different doses of the drug and the increase in tail-flick latencies.

\section{Motor effects of WIN 55,212-2 in awake animals}

As expected from previous research (Loewe, 1946; Gough and Olley, 1977; Ueki, 1980), WIN 55,212-2 (0.25 mg/kg, i.v.) induced motor impairment in both tests of motor function. WIN 55,212-2 $(0.25 \mathrm{mg} / \mathrm{kg}$, i.v. $)$ produced a significant decrease in running time in the rotorod test $\left(F_{(4,56)}=4.25, p<0.01\right)$. Likewise, four of six animals treated with the drug showed maximum effects $(60 \mathrm{sec}$ cutoff latency) in the test of catalepsy, and all animals showed increased descent latency compared with the predrug injection $(p=0.016)$.

The main finding of interest in these experiments was the shorter duration of the effect of the drug on motor function (catalepsy and rotorod) than on responses to noxious stimulation (paw withdrawal, tail flick, and noxious stimulus-evoked firing).

Table 1. Comparison of the time course of the $0.25 \mathrm{mg} / \mathrm{kg}$ dose of WIN $55,212-2$ on motor, nociceptive, and electrophysiological activity

\begin{tabular}{lcl} 
Measure & $\begin{array}{l}\text { Minutes to recovery to } \\
\text { within 20\% of baseline } \\
\text { value (mean } \pm \text { SEM) }\end{array}$ & Anesthesia \\
\hline Catalepsy & $4.5 \pm 1.5$ & None \\
Rotorod & $13 \pm 5.6$ & None \\
Tail flick & $28 \pm 2.1^{a, b}$ & None \\
$\begin{array}{l}\text { Noxious stimulus- } \\
\quad \text { evoked neuronal activity }\end{array}$ & $35 \pm 7.6^{a}$ & \\
Paw withdrawal & $38 \pm 8.5^{a, b}$ & $\begin{array}{l}\text { Surgical } \\
\text { Sedation }\end{array}$
\end{tabular}

ANOVA revealed a significant difference between the mean recovery times for each measure. Comparisons between measures were determined by Bonferroni post hoc comparison using pooled variance.

${ }^{a}$ Time course significantly different ( $p<0.05$, Newman-Keuls test) from rotorod and catalepsy.

${ }^{b}$ Time course not significantly different from cannabinoid-induced-inhibition of noxious stimulus-evoked neuronal activity. 


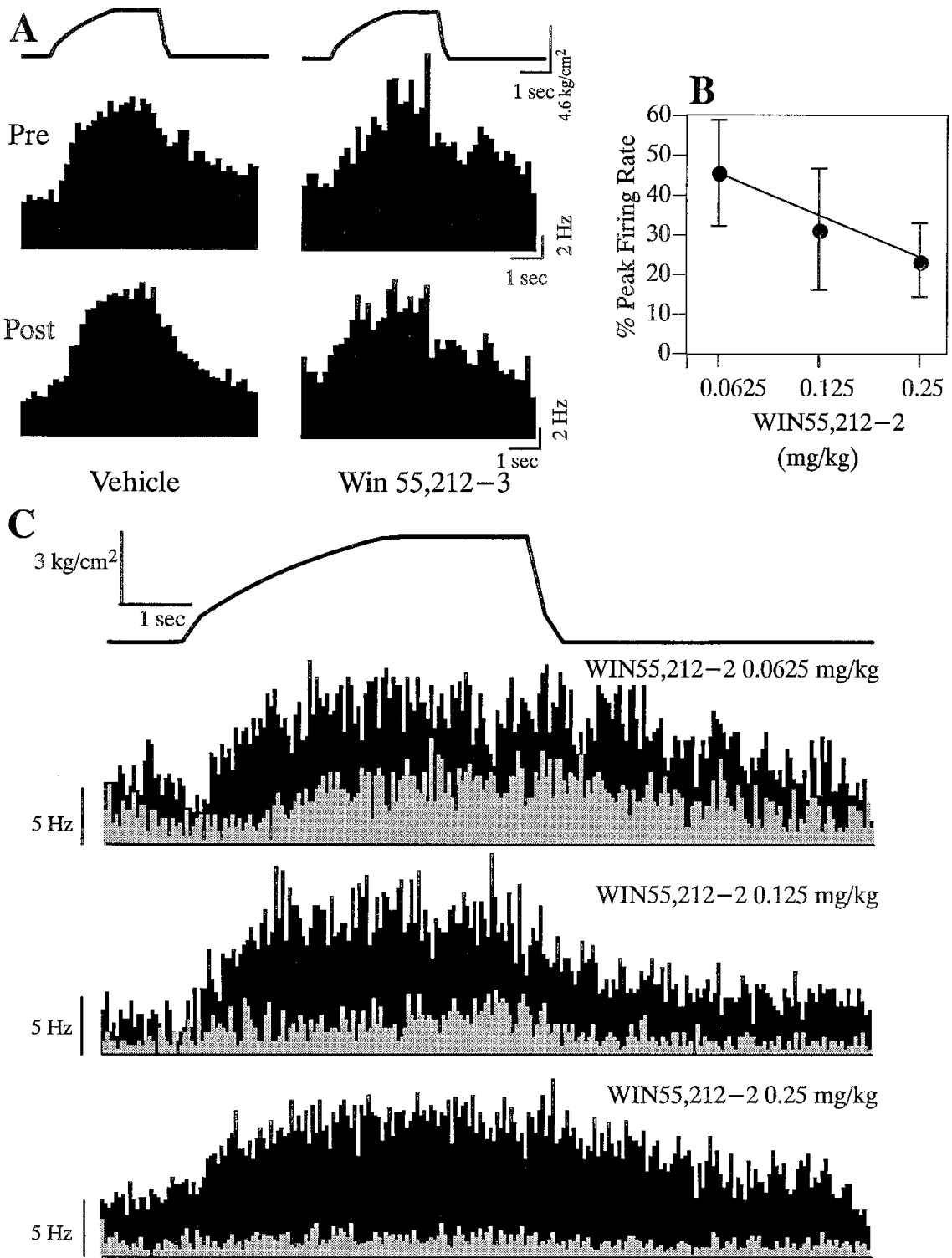

Figure 3. A, Spontaneous and evoked firing before and after administration of the vehicle $(n=6)$ or the cannabinoid receptor-inactive compound WIN 55,212-3 $(n=4)$. Top, Level of the applied pressure in register with the PSTHs below. Middle and bottom, Average of 10 predrug (middle) and 10 postdrug (bottom) firing rate histograms. Neither the vehicle nor the inactive enantiomer WIN 55,212-3 produced an effect on spontaneous or evoked firing. $B$, Inhibition of peak evoked-activity by various doses of WIN 55,212-2. $C$, Dose-dependent decreases in the responsiveness of VPL neurons to a noxious pressure stimulus after administration of the cannabinoid agonist WIN 55,212-2. Top center, Line over the histograms showing the pressure applied to the paw at various times. Bottom three histograms, Black histograms represent the group mean response during $10 \mathrm{~min}$ before drug administration; gray histograms represent the mean response during 10 min after administration WIN 55,212-2.

One-way ANOVA revealed significant differences in the duration of the effects of WIN 55,212-2 on the various measures, which were determined for each animal as the amount of time during which responses deviated by $>20 \%$ from the individual's mean predrug response $\left(F_{(4,27)}=6.00, p=0.0014\right)$ (Fig. 10). Comparisons between all pairs of means using the Newman-Keuls post $h o c$ test revealed that the duration of the drug effect did not differ between the measures of motor function (catalepsy and rotorod). Likewise, the duration of the drug effect did not differ among responses to different types of noxious stimulation (tail flick, paw withdrawal, electrophysiology). However, the duration of the effect of the drug on each measure of motor function was shorter than the effect on each measure of responsiveness to noxious stimuli (Table 1$)$ ( $p<0.05$ for all comparisons). These differences in time course were independent of the state of anesthesia, because the duration of drug-induced changes in sensory responses were not significantly different in awake (tail flick), sedated (paw withdrawal), and deeply anesthetized (electrophysiology) rats.

\section{DISCUSSION}

The cannabinoid receptor agonist WIN 55,212-2 inhibited stimulus-evoked activity of nociceptive neurons in the VPL. It appears that the drug had a selective effect on nociceptive neurons, because it produced greater inhibition of noxious stimulusevoked firing than spontaneous firing and failed to alter the activity of non-nociceptive mechanosensitive neurons in the VPL. It appears that these effects were mediated by cannabinoid receptors, because they were potent, dose-dependent, reversible, and not produced by the receptor-inactive enantiomer or the vehicle.

Previous studies from our laboratory have provided evidence for a role of cannabinoids in the processing of nociceptive information. For example, systemic administration of WIN 55,212-2 suppressed both noxious stimulus-evoked expression of c-fos in the spinal dorsal horn and pain-related behavior (Tsou et al., 1996). The role of cannabinoid receptors was suggested by the lack of effect in animals rendered tolerant to cannabinoids and by the lack of effect of the receptor-inactive enantiomer WIN 55,212-3. A separate study showed that WIN 55,212-2 selectively 


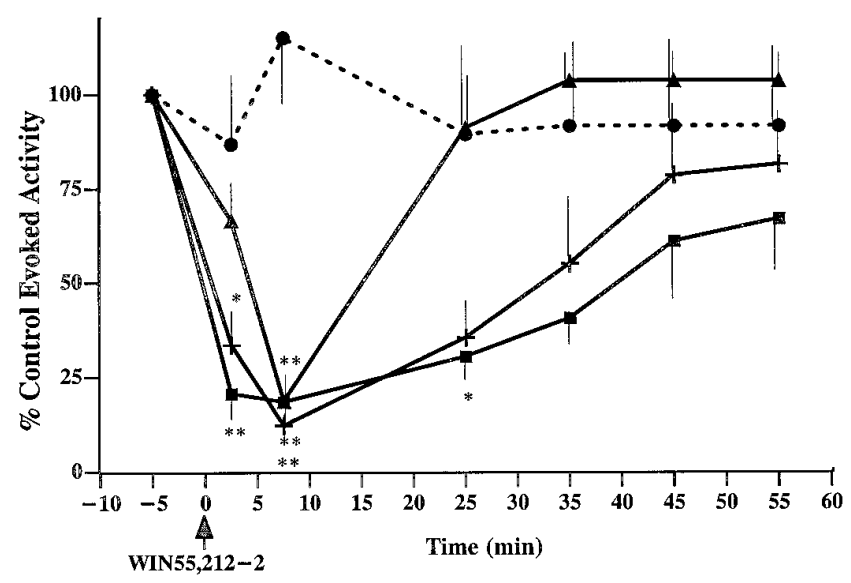

Figure 4. Evoked firing over time before and after intravenous administration of the vehicle or a dose of WIN 55,212-2. Vehicle (filled circles) injections had no effect on noxious stimulus-evoked activity. The cannabinoid agonist produced marked dose-dependent differences in evoked firing during the later periods: $0.0625 \mathrm{mg} / \mathrm{kg}$ (filled triangles), $0.125 \mathrm{mg} / \mathrm{kg}$ (plus signs), $0.25 \mathrm{mg} / \mathrm{kg}$ (filled squares) WIN 55,212-2. Asterisks, Significantly different from control: ${ }^{*} p<0.05{ }^{* *} p<0.01$ (Dunnet test). See text for additional details on the statistical analysis of this experiment.

inhibited noxious stimulus-evoked responses of wide dynamic range neurons in the dorsal horn of the spinal cord without affecting the responses of non-nociceptive neurons (Hohmann et al., 1995). The finding in this study that similar effects occur in the thalamus supports our previous work and suggests that at least some of the dorsal horn neurons recorded previously were spinothalamic tract neurons.

As expected from previous research (Tsou and Chang, 1964; Calvillo et al., 1974; Kitahata et al., 1974; Hill and Pepper, 1978; Benoist et al., 1983; Homma et al., 1983), morphine suppressed noxious stimulus-evoked firing in VPL. A comparison of WIN 55,212-2 with morphine indicates that the effects of these compounds were very similar. Both WIN 55,212-2 and morphine reduced non-noxious and noxious stimulus-evoked activity in VPL

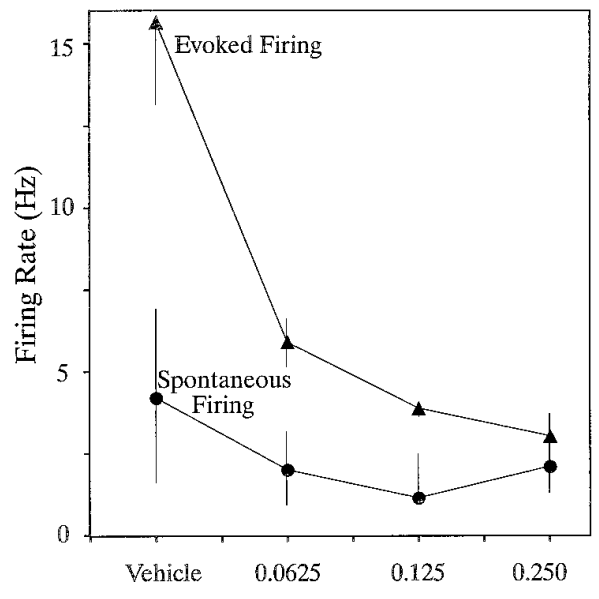

Dose WIN 55,212-2 (mg/kg, i.p.)

Figure 5. Effect of various doses of WIN 55,212-2 on spontaneous and noxious stimulus-evoked activity. Firing rate (averaged over 10 stimulus presentations after drug injection) during the $1 \mathrm{sec}$ preceding the stimulus (Spontaneous Firing) and the last (most noxious) $1 \mathrm{sec}$ of stimulation. ANOVA revealed a significantly greater effect on evoked compared with spontaneous firing. Vertical lines represent SEMs.

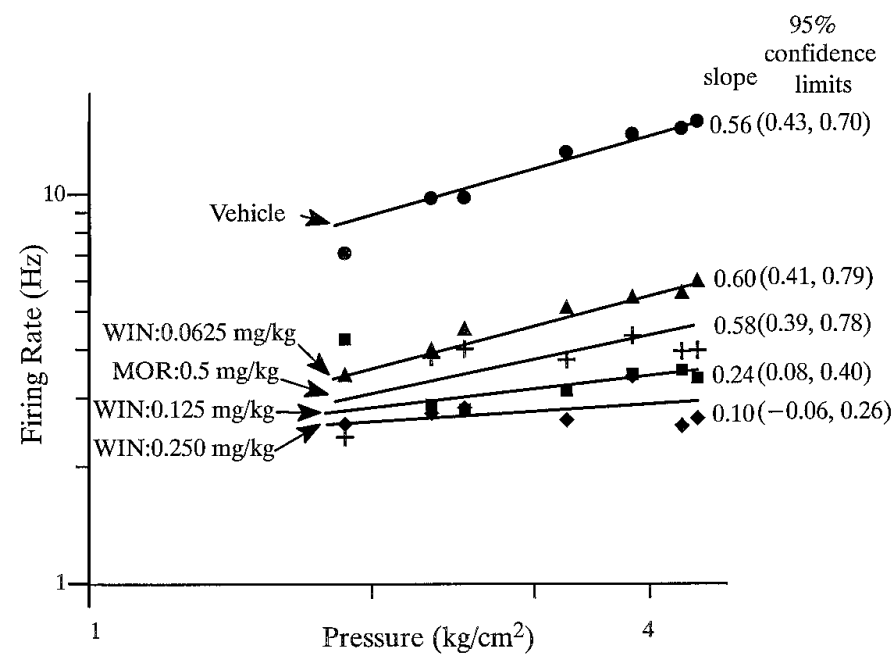

Figure 6. Mean stimulus-response functions after administration of vehicle (filled circles), WIN 55,212-2 [0.0625 mg/kg (filled triangles), 0.125 $\mathrm{mg} / \mathrm{kg}$ (filled squares), or $0.25 \mathrm{mg} / \mathrm{kg}$ (filled diamonds)] or morphine (plus signs). The lowest dose of the drug $(0.0625 \mathrm{mg} / \mathrm{kg})$ reduced the overall firing but did not alter the slope of the stimulus-response function. Morphine $(0.5 \mathrm{mg} / \mathrm{kg})$ showed a similar effect. Significant decreases in slope occurred at higher doses of WIN 55,212-2 $(0.125$ and $0.25 \mathrm{mg} / \mathrm{kg})$. Postinjection slope values and confidence limits for estimation of $\beta$ were determined as described in Materials and Methods.

neurons, and both compounds produced a similar maximum effect: nearly complete inhibition of noxious stimulus-evoked firing. The similar efficacy of the two classes of compounds observed in this study supports previous behavioral studies that found comparable analgesic efficacy of the two classes of compounds (Buxbaum, 1972; Bloom, 1977; Jacob et al., 1981). Although cannabinoids and opiates produce similar effects on nociception, there is little evidence for a direct interaction of cannabinoids with opiate receptors (for review, see Martin, 1986). Nonetheless, it does appear that the two systems may share some neural substrates at either a cellular level or via common actions on neurochemicals known to modulate pain perception (Gascon and Bensemana, 1975; Welch et al., 1995).

The suppressive effect of WIN 55,212-2 on noxious stimulusevoked activity does not represent an anesthetic effect of the drug,

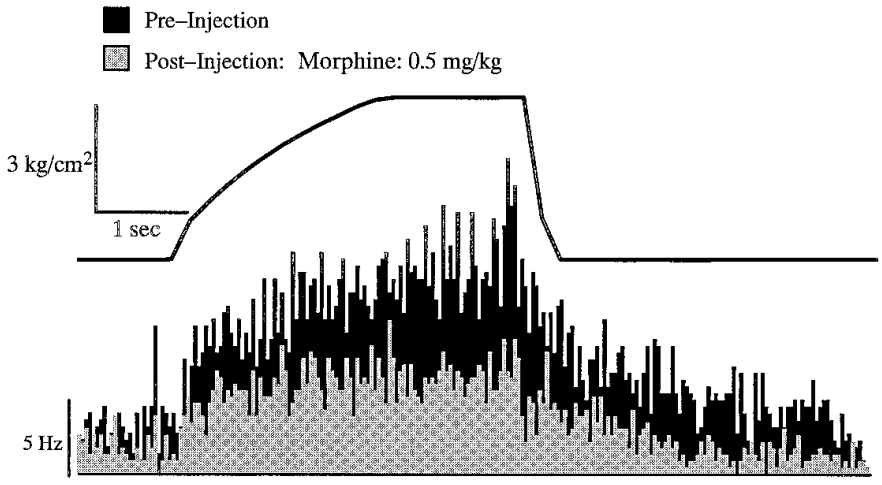

Figure 7. PSTH illustrating the effect of morphine $(0.5 \mathrm{mg} / \mathrm{kg}$, i.v. $)$ on stimulus-evoked activity in the VPL. Top center, Line over the histograms showing the pressure applied to the paw at various times. Bottom, Black histograms represent the group mean response during $10 \mathrm{~min}$ before drug administration; gray histograms represent the mean response during 10 min after administration of morphine. As shown, morphine markedly reduced stimulus-evoked activity. 


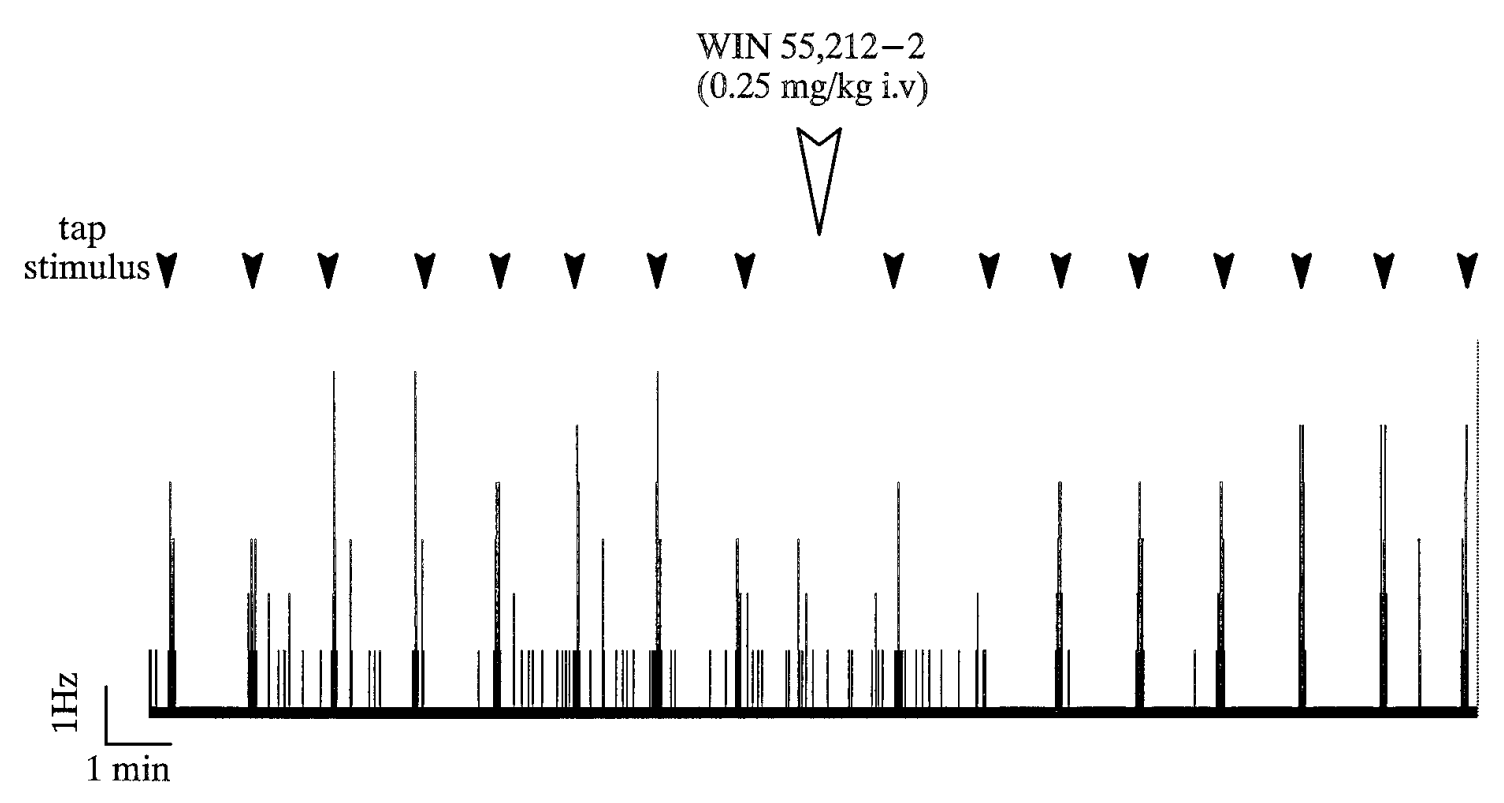

Figure 8. Firing rate histogram of mechanosensitive non-nociceptive neuron before and after administration (open triangle) of WIN $55,212-2(0.25 \mathrm{mg} / \mathrm{kg}$, i.v.). The cannabinoid agonist did not significantly reduce the responses of mechanosensitive neurons to tap stimuli ( filled triangles) administered every minute. Note the reduction in spontaneous activity after the drug and the more robust response to the stimulus in this cell after the drug.

because it failed to alter the evoked activity of non-nociceptive mechanoreceptive neurons in the same area. Furthermore, the cannabinoid agonist had a greater effect on evoked firing than on spontaneous firing. The lack of effect of the drug on nonnociceptive mechanosensitive neurons in the VPL is consistent with the previous failure of a cannabinoid to affect nonnociceptive mechanosensitive neurons in the spinal dorsal horn (Hohmann et al., 1995). These findings suggest that the effect of the cannabinoid on nociceptive neurons is selective.

The drug-induced decrease in electrophysiological and behavioral sensitivity to noxious stimuli outlasted the impairment of motor function, providing evidence for a dissociation between cannabinoid-induced changes in motor and pain-related behavior. Thus, profound analgesia and suppression of electrophysiological responses to noxious stimuli occurred during periods when motor impairment was minimal. Because the potency of WIN 55,212-2 in tests of analgesia is much greater than its potency in tests of motor function (Abood and Martin, 1992), one would expect the analgesic effect to outlast the motor impairment. These findings provide a strong basis for the conclusion that the actions of WIN $55,212-2$ on pain and movement are mediated by separate processes and suggest that the decreased behavioral responsiveness to noxious stimuli does not result merely from a disruption of motor function. This conclusion is supported by studies that demonstrated antinociceptive actions of cannabinoids in a test (vocalization to shock) that does not require a gross motor response (Ferri et al., 1981, 1986).

The effects observed in these experiments cannot be accounted for by changes in skin temperature, because skin temperature was unchanged by the drug under the conditions used in the electrophysiological experiments. Presumably, the automatic heating circuitry prevented any such effects. In the behavioral experiments, the change in tail-flick latency was not attributable to a change in tail temperature, because the small change observed lasted for only one-tenth the duration of the change in tail-flick latency and could not be attributed to the drug. Moreover, the increase in tail temperature observed would be expected to lead to an artifactual decrease in tail-flick latency (an apparent hyperalgesic state) (Tjolsen et al., 1989), an effect opposite to the observed increase.

The relationship between the electrophysiological, antinociceptive, and motor effects of WIN 55,212-2 also cannot be accounted for by the level of anesthesia used in the experiments. No significant differences were found among the time courses of the changes in tail-flick latency (awake), paw-withdrawal latency (sedation), or the electrophysiological effects (surgical anesthesia). However, the duration of the effect on the tail-flick reflex (awake), paw-withdrawal reflex (sedation), and evoked firing (surgical anesthesia) was significantly greater than the duration of the effects on rotorod performance (awake) and catalepsy (awake). If the differences in time course were the result of anesthesia, one would expect catalepsy, rotorod, and tail flick to be similar; paw withdrawal intermediate; and noxious stimulus-evoked firing the longest. This clearly did not occur. Thus, the shorter duration of the cannabinoid effect on motor behavior compared with nociceptive responsiveness cannot be accounted for by a faster clearance of the drug during the waking state. These findings demonstrate that the differences in the time course of motor impairment compared with behavioral antinociception and thalamic electrophysiology reflect actions at a neural systems level rather than merely an artifact of anesthesia.

The site of action of WIN 55,212-2 was not investigated in this study; however, this is an important question for future investigations. Previous behavioral studies suggested that cannabinoid receptor-mediated antinociception is mediated by both spinal and supraspinal sites (Yaksh, 1981; Lichtman and Martin, 1991; Smith and Martin, 1991; Martin et al., 1993), consistent with the presence of cannabinoid receptors in brain and spinal areas that modulate the transmission of nociceptive information (e.g., the spinal dorsal horn and periaqueductal gray) (Herkenham et al., 1991). Recent work from this laboratory demonstrated that microinjections of a low dose of WIN 55,212-2 into the periaqueductal gray or dorsal raphe nucleus elevate tail-flick latencies (Martin et al., 1995). Kayser and co-workers (1983) reported that microinjections of morphine into these areas also depress noci- 

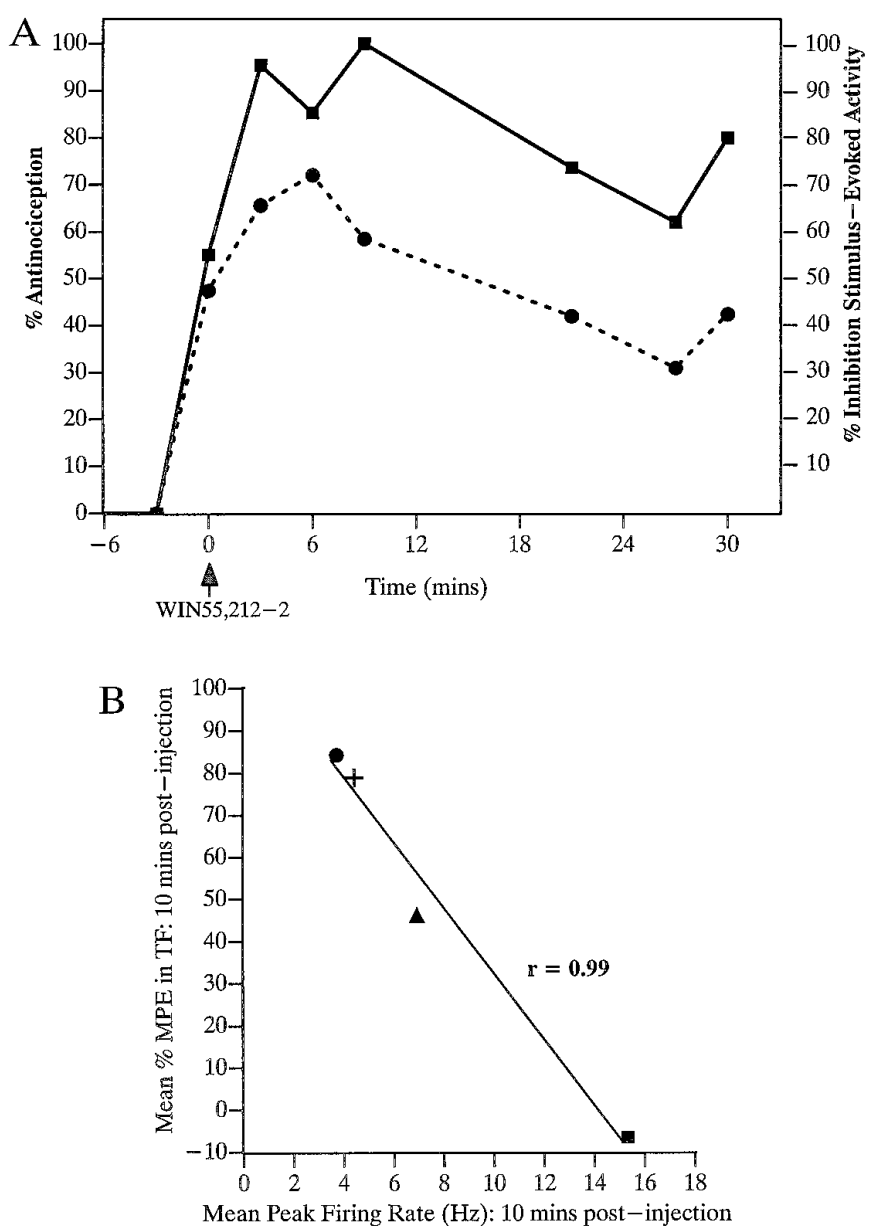

Figure 9. A, Time course of the antinociceptive and electrophysiological effects of WIN 55,212-2 (0.25 mg/kg, i.v.). Antinociception was assessed as the pressure at which rats (lightly anesthetized) exhibited a withdrawal response to a mechanical stimulus that increased in intensity over time, as described in the text. Data are presented as percent antinociception. For electrophysiology experiments (in separate animals under surgical anesthesia), the same mechanical stimulus was used to apply pressure to the contralateral hindpaw, whereas stimulus-evoked activity was recorded from individual neurons in the VPL. The effects of WIN 55,212-2 are presented as percent inhibition of stimulus-evoked activity relative to preinjection values. Note that the inhibition of paw withdrawal (filled circles) (as percent antinociception) parallels the inhibition of stimulusevoked activity (filled squares) in VPL neurons. B, The relationship between inhibition of noxious-stimulus-evoked activity and inhibition of tail-flick reflex were determined using regression analysis. For each procedure, vehicle (filled square) or WIN 55,212-2 [0.0625 mg/kg (filled triangle), $0.125 \mathrm{mg} / \mathrm{kg}$ ( plus sign), or $0.25 \mathrm{mg} / \mathrm{kg}$ (filled circle)] was administered to separate groups of animals. Tail-flick data (awake animals) are presented as mean \%MPE during the 10 min after injection. Electrophysiology data are presented as mean peak firing rate during the 10 min after injection. The high correlation $(r=0.99)$ is indicative of a relationship between the behavioral and the electrophysiological responses.

ceptive responses of ventrobasal thalamic neurons. Thus, the periaqueductal gray and dorsal raphe are potential mediators of the effects we observed.

In summary, the results of this study demonstrate that cannabinoids reduce sensory transmission within an important ascending nociceptive pathway. These effects were mediated by cannabinoid receptors and followed a time course that was indistinguishable from that of the analgesic effects of the drug but different from that of the motor effects. The alteration in the

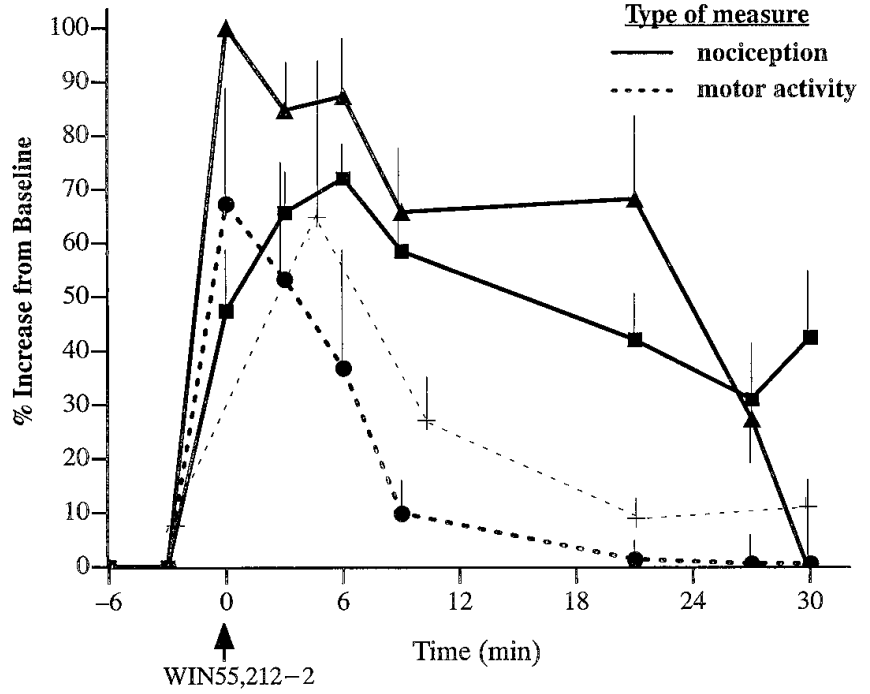

Figure 10. Effect of WIN 55,212-2 (0.25 mg/kg, i.v.) on two measures of nociception (solid lines) and two measures of motor activity (dashed lines). WIN 55,212-2 impaired motor function in tests of both ataxia (plus signs) and catalepsy (filled circles). However, the antinociceptive effects produced by WIN 55,212-2 in the paw-withdrawal (filled squares) and tail-flick (filled triangles) tests significantly outlasted the impairment of motor function, which suggests mediation of these effects by separate processes. Data are presented as percent increase from baseline.

stimulus-response functions of nociceptive neurons produced by WIN 55,212-2 was very similar to that produced by morphine, a powerful narcotic analgesic. These findings suggest a possible role of the endogenous cannabinoid anandamide in pain modulation. If this substance serves as a cannabinoid neurotransmitter, it would appear that one of its functions is to modulate pain transmission by decreasing the sensory responsiveness of neurons within the spinothalamic pathway. The circumstances under which anandamide is released and its site(s) of action remain important topics for future investigations.

\section{REFERENCES}

Abood ME, Martin BR (1992) Neurobiology of marijuana abuse. Trends Pharmacol Sci 131:201-206.

Angel A, Clark KA (1975) An analysis of the representation of the forelimb in the ventrobasal thalamic complex of the albino rat. J Physiol (Lond) 249:399-423.

Benoist JM, Kayser V, Gautron M, Guilbaud G (1983) Low dose of morphine strongly depresses responses of specific nociceptive neurones in the ventrobasal complex of the rat. Pain 15:333-344.

Besse D, Lombard MC, Besson JM (1991) Autoradiographic distribution of mu, delta and kappa opioid binding sites in the superficial dorsal horn, over the rostrocaudal axis of the rat spinal cord. Brain Res 548:287-291.

Bloom AS, Dewey WL, Harris LS, Brosius KK (1977) 9-nor-9bhydroxyhexahydrocanninol, a cannabinoid with potent antinociceptive activity: comparisons with morphine. J Pharmacol Exp Ther 200:263-270.

Buxbaum DM (1972) Analgesic activity of $\Delta^{9}$-tetrahydrocannabinol in the rat and mouse. Psychopharmacology (Berl) 25:275-280.

Cartmell SM, Gelgor L, Mitchell D (1991) A revised rotarod procedure for measuring the effect of antinociceptive drugs on motor function in the rat. J Pharmacol Methods 26:149-159.

Cavillo O, Henry JL, Neuman RS (1974) Effects of morphine and naloxone on dorsal horn neurons in the cat. Can J Physiol Pharmacol 52:1207-1211.

Compton DR, Gold LH, Ward SJ, Balster RL, Martin BR (1992) Aminoalkylindole analogs: cannabimimetic activity of a class of compounds 
structurally distinct from delta 9-tetrahydrocannabinol. J Pharmacol Exp Ther 263:1118-1126.

D'Ambra TE, Estep KG, Bell MR, Eissenstat MA, Josef KA, Ward SJ, Haycock DA, Baizman ER, Casiano FM, Beglin NC, Chippari SM, Grego JD, Kullnig RK, Daley GT (1992) Conformationally restrained analogues of pravadoline: nanomolar potent, enantioselective, (aminoalkyl)indole agonists of the cannabinoid receptor, J Med Chem 35:124-135.

D'Amour FE, Smith DL (1941) A method for determining loss of pain sensation. J Pharmacol Exp Ther 72:74-79.

Devane WA, Hanus L, Breuer A, Pertwee RG, Stevenson LS, Griffin G, Gibson D, Mandelbaum A, Etinger A, Mechoulam R (1992) Isolation and structure of a brain constituent that binds to the cannabinoid receptor. Science 258:1946-1949.

Dong WK, Ryu H, Wagman IH (1978) Nociceptive responses of neurons in medial thalamus and their relationship to spinothalamic pathways. J Neurophysiol 41:1592-1613.

Dunham NW, Miya TS (1957) A note on a simple apparatus for detecting neurological deficit in rats and mice. J Am Pharm Assoc 46:208-209.

Edwards A (1984) An introduction to linear regression and correlation, 2nd ed, pp 88-93. New York: Freeman.

Faull RL, Villiger JW (1987) Opiate receptors in the human spinal cord: a detailed anatomical study comparing the autoradiographic localization of $\left[{ }^{3} \mathrm{H}\right]$ diprenorphine binding sites with the laminar pattern of substance P, myelin and nissl staining. Neuroscience 20:395-407.

Felder CC, Joyce KE, Briley EM, Mansouri J, Mackie K, Blond O, Lai Y, Ma AL, Mitchell RL (1995) Comparison of the pharmacology and signal transduction of the human cannabinoid $\mathrm{CB}_{1}$ and $\mathrm{CB}_{2}$ receptors. Mol Pharmacol 48:443-450.

Ferri S, Costa G, Murai G, Panico AM, Speroni E, Arrigo Reina R (1981) Investigation on the behavioral effects of an extract of Cannabis sativa in the rat. Psychopharmacology 75:144-147.

Ferri S, Cavichinni E, Romualdi P, Speroni E, Murari G (1986) Possible mediation of catecholiminergic pathways in the antinociceptive effect of an extract of Cannabis sativa L. Psychopharmacology 89:244-247.

Gascon AL, Bensemana D (1975) An attempt to correlate analgesia to changes in brain neuromediators in rats. Res Commun Chem Pathol Pharmacol 12:449-463.

Giesler Jr GJ, Menetrey D, Guilbaud G, Besson J-M (1976) Lumbar cord neurons at the origin of the spinothalamic tract in the rat. Brain Res 118:320-324.

Goldstein A (1964) Biostatistics: an introductory text. New York: Macmillan.

Gough AL, Olley JE (1977) $\Delta^{9}$-Tetrahydrocannabinol and the extrapyramidal system. Psychopharmacology 54:87-99.

Greenhouse SW, Geisser S (1959) On methods in the analysis of profile data. Psychometrika 24:95-112.

Guilbaud G, Peschanski M, Gautron M, Binder D (1980) Neurones responding to noxious stimulation in $\mathrm{VB}$ complex and caudal adjacent regions in the thalamus of the rat. Pain 8:303-318.

Guilbaud G, Benoist JM, Neil A, Kayser V, Gautron M (1987) Neuronal response thresholds to and encoding of thermal stimuli during carrageenin-hyperalgesic-inflammation in the ventro-basal thalamus of the rat. Exp Brain Res 66:421-431.

Herkenham M (1995) Localization of cannabinoid receptors in brain and periphery. In: Cannabinoid receptors (Pertwee RG, ed), pp 1455-1466. New York: Academic.

Herkenham M, Lynn AB, Johnson MR, Melvin LS, de Costa BR, Rice KC (1991) Characterization and localization of cannabinoid receptors in rat brain: a quantitative in vitro autoradiographic study. J Neurosci 11:563-583.

Hill RG, Pepper CM (1978) Selective effects of morphine on the nociceptive responses of thalamic neurones in the rat. $\mathrm{Br} \mathrm{J}$ Pharmacol 64:137-143.

Hohmann AG, Martin WJ, Tsou K, Walker JM (1995) Inhibition of noxious-evoked activity of spinal cord dorsal horn neurons by the cannabinoid WIN55,212-2. Life Sci 56:2111-2119.

Homma E, Colins JG, Kitahata LM, Matsumoto M, Kawahara M (1983) Suppression of noxiously evoked WDR dorsal horn neuronal activity by spinally administered morphine. Anesthesiology 58:232-236.

Howlett AC, Bidaut-Russell M, Devane WA, Melvin S, Johnson MR, Herkenham M (1990) The cannabinoid receptor: biochemical, anatomical, and behavioral characterization. Trends Neurosci 13:420-423.
Jacob J, Ramabadran K, Campos-Medeiros M (1981) A pharmacological analysis of levonantradol antinociception in mice. J Clin Pharmacol 21:327S-333S.

Jansen EM, Haycock DA, Ward SJ, Seybold VS (1992) Distribution of cannabinoid receptors in rat brain determined with aminoalkylindoles. Brain Res 575:93-102.

Kayser V, Benoist J-M, Guilbaud G (1983) Low dose of morphine microinjected in the ventral periaqueductal gray matter of the rat depresses responses of nociceptive ventrobasal thalamic neurons. Neurosci Lett 37:193-198.

Kinnard Jr WJ, Carr CJ (1957) A preliminary procedure for the evaluation of central nervous system depressants. J Pharmacol Exp Ther 121:354-361.

Kitahata LM, Kosaka Y, Taub A, Bonikos K, Hoffert M (1974) Laminaspecific suppression of dorsal-horn unit activity by morphine sulfate. Anesthesiology 41:39-48.

Lichtman AH, Martin BR (1991a) Spinal and supraspinal components of cannabinoid-induced antinociception. J Pharmacol Exp Ther 258: 517-523.

Lichtman AH, Martin BR (1991b) Cannabinoid-induced antinociception is mediated by a spinal alpha 2-noradrenergic mechanism. Brain Res 559:309-314.

Loewe S (1946) Studies on the pharmacology and acute toxicity of compounds with marihuana activity. J Pharmacol Exp Ther 88:154-161.

Lund RD, Webster KE (1967) Thalamic afferents from the dorsal column nuclei: an experimental anatomical study in the rat. J Comp Neurol 130:301-312.

Martin BR (1986) Cellular effects of cannabinoids. Pharmacol Rev 38:45-73.

Martin WJ, Lai NK, Patrick SL, Tsou K, Walker JM (1993) Antinociceptive actions of cannabinoids following intraventricular administration in rats. Brain Res 629:300-304.

Martin WJ, Patrick SL, Coffin PO, Tsou K, Walker JM (1995) An examination of the central sites of action of cannabinoid-induced antinociception in the rat. Life Sci. Life Sci 56:2103-2110.

McAllister JP, Wells J (1981) The structural organization of the ventral posterolateral nucleus in the rat. J Comp Neurol 197:271-301.

Mendell LM (1966) Physiological properties of unmyelinated fiber projection to the spinal cord. Exp Neurol 16:316-332.

Miletic V, Coffield JA (1989) Responses of neurons in the rat nucleus submedius to noxious and innocuous mechanical cutaneous stimulation. Somatosens Mot Res 6:567-587.

Miller AM, Walker JM (1995) Effects of a cannabinoid on spontaneous and evoked activity in the substantia nigra pars reticulata. Eur J Pharmacol 279:179-185.

Mitchell D, Hellon RF (1977) Neuronal and behavioral responses in rats during noxious stimulation of the tail. Proc R Soc Lond [Biol] 197:169-194.

Montagne-Clavel J, Oliveras J-L (1995) Does barbiturate anesthesia modify the neuronal properties of the somatosensory thalamus? A single-unit study related to nociception in the awake-pentobarbitaltreated rat. Neurosci Lett 196:69-72.

Moss DE, Johnson RL (1980) Tonic analgesic effects of $\Delta^{9}$ tetrahydrocannabinol as measured with the formalin test. Eur J Pharmacol 61:313-315.

Myers JL (1972) Fundamentals of experimental design, p 116. Boston: Allyn and Bacon.

Paxinos G, Watson C (1986) The rat brain in stereotaxic coordinates, 2nd ed. New York: Academic.

Peschanski M, Besson J-M (1984) A spino-reticulo-thalamic pathway in the rat: an anatomical study with reference to pain transmission. Neuroscience 12:165-178.

Peschanski M, Guilbaud G, Gautron M (1980a) Neuronal responses to cutaneous electrical and noxious mechanical stimuli in the nucleus reticularis thalami of the rat. Neurosci Lett 20:165-170.

Peschanski M, Guilbaud G, Gautron M, Besson J-M (1980b) Encoding of noxious heat messages in neurons of the ventrobasal thalamic complex of the rat. Brain Res 197:401-413.

Peschanski M, Guilbaud G, Gautron M (1981) Posterior intralaminar region in rat: neuronal responses to noxious and non-noxious cutaneous stimuli. Exp Neurol 72:226-238.

Peschanski M, Mantyh PW, Besson J-M (1983) Spinal afferents to the ventrobasal thalamic complex in the rat: an anatomical study using wheat-germ agglutinin conjugated to horseradish peroxidase. Brain Res 278:240-244. 
Pertwee RG (1993) The evidence for the existence of cannabinoid receptors. Gen Pharmacol 24:811-824.

Pertwee RG, Wickens AP (1991) Enhancement by chlordiazepoxide of catalepsy induced in rats by intravenous or intrapallidal injections of enantiomeric cannabinoids. Neuropharmacology 30:237-244.

Pertwee RG, Stevenson LA, Griffin G (1993) Cross-tolerance between delta-9-tetrahydrocannabinol and the cannabimimetic agents, CP55940, WIN55212-2 and anadamide. Br J Pharmacol 110:1483-1490.

Price DD (1988) Psychological and neural mechanisms of pain. New York: Raven.

Smith PB, Martin BR (1991) Spinal mechanisms of $\Delta^{9}$-tetrahydrocannabinolinduced analgesia. Brain Res 578:8-12.

Sofia RD, Nalepa SD, Harakal JJ, Vassar HB (1973) Anti-edema and analgesic properties of $\Delta^{9}$-tetrahydrocannabinol (THC). J Pharmacol Exp Ther 186:646-655.

Tjolsen A, Lund A, Eide PK, Berge OG, Hole K (1989) The apparent hyperalgesic effect of a serotonin antagonist in the tail flick test is mainly due to increased tail skin temperature. Pharmacol Biochem Behav 32:601-605.
Tsou K, Chang ZL (1964) Morphine effects on spinal cord electrical activity. Acta Physiol Sin 27:369-377.

Tsou K, Lowitz KA, Hohmann AG, Martin WJ, Hathaway CB, Bereiter DA, Walker JM (1996) Suppression of noxious stimulus-evoked expression of fos-like immunoreactivity in rat spinal cord by a selective cannabinoid agonist. Neuroscience 70:791-798.

Ueki S (1980) Abnormal behavior induced by $\Delta^{9}$-tetrahydrocannabinol and its pharmacological characteristics. Trends Pharmacol Sci 1:126-129.

Welch SP, Thomas C, Patrick GS (1995) Modulation of cannabinoidinduced antinociception after intracerebroventricular versus intrathecal administration to mice: possible mechanisms for interaction with morphine. J Pharmacol Exp Ther 272:310-321.

Willis WD (1984) The origin and destination of pathways involved in pain transmission. In: Textbook of pain (Wall PD, Melzack R, eds), pp 88-99. Edinburgh: Churchill Livingstone.

Yaksh TL (1981) The antinociceptive effects of intrathecally administered levonantradol and desacetyllevonantradol in the rat. J Clin Pharmacol 21:334S-340S. 